\title{
Degradation of $S$-metolachlor in soil as affected by environmental factors
}

\author{
Y.H.Long ${ }^{1,2}$, R.Y.Li ${ }^{1}$, X.M.Wu ${ }^{1}$,* $^{*}$ \\ ${ }^{1}$ Department of Plant Protection, Agriculture College, Guizhou University, Huaxi District Guiyang 550025, People's \\ Republic of China. ${ }^{2}$ Guizhou Key Laboratory for tobacco quality, Huaxi District Guiyang 550025, People's Republic \\ of China. *Corresponding author: wuxm827@126.com
}

\begin{abstract}
$S$-Metolachlor is a promising alternative to metolachlor; however, there are concerns about its environmental fate following soil application. The present study was conducted to investigate the effects of several environmental factors on the degradation rate of $S$-metolachlor in soil. The rate of $S$-metolachlor degradation in soil under different conditions was determined by extracting and detecting residual levels over a $60 \mathrm{~d}$ incubation period. Degradation of $S$-metolachlor in the five tested soils followed the first-order kinetics, yielding the half-lives $\left(T_{1 / 2}\right)$ varying from 26.3 to $40.1 \mathrm{~d}$, which was significantly controlled by soil organic matter (OM) content. The degradation rate of $S$-metolachlor in 1\#soil increased with increasing temperature. The first-order half-lives ranged from $23.7 \mathrm{~d}$ at 35 ${ }^{\circ} \mathrm{C}$ to $64.8 \mathrm{~d}$ at $10{ }^{\circ} \mathrm{C}$. Soil moisture content influenced the rate of herbicide degradation in the following order: $80>60>40>20 \%$ for $1 \#$ soil. The degradation rate of $S$-metolachlor in sterilized soil was 3.3 times slower than in corresponding unsterilized soil, indicating that microbial degradation was the predominant contributors to dissipation of $S$-metolachlor in soil. The degradation rate of $S$-metolachlor decreased as the initial concentration increased. These findings might have practical implications for the environmental fate of $S$-metolachlor in the agricultural soil. Environmental factors, especially soil OM, temperature and moisture, should be considered in combination with the minimum effective application rate of $S$-metolachlor for achieving satisfactory weed-control efficacy, reducing herbicide runoff, and minimizing effects on environmental quality.
\end{abstract}

Keywords: S-Metolachlor, soil, degradation, environmental factor

\section{Introduction}

Increasing herbicides loadings on agricultural and non-crop environments have resulted in extensive research on the fate and transport of these agricultural chemicals. Considerable amount of evidence shows that the environmental fate of herbicides in soil involves complex mechanisms that are influenced by many processes, including volatilization, leaching, adsorption, and degradation. Of these processes, degradation is one of the key processes determining whether herbicide use will have any effect on environmental quality as well as efficacy for weed control (Wang et al., 1999; Zheng et al., 1996; Rice et al., 2002; Shaner et al., 2006; Si et al., 2009). Degradation of herbicides, in general, is influenced 
by soil properties, herbicide characteristics and by climatic conditions (Baker and Mickelson, 1994; Baer and Calvet, 1999; Rice et al., 2002; Shelton and Parkin, 1991;Taylor-Lovell, et al., 2002; Gaultier et al., 2008; Si et al., 2009; Wu et al, 2011). Increasing persistence of herbicide residues in soil will increase the probability of transport of herbicides lost from fields to surface and ground water resources. The presence of herbicide residues in surface and ground water, and in food has heightened public interest regarding the persistence and toxicological significance of these field-applied herbicides (Frank et al., 1990; Thurman et al., 1992; Kalkhoff et al., 1998). Thus, it is important to characterize degradation of a certain herbicide in soil, to increase the precision with which safer herbicide uses and potential issues of concern can be identified. $S$-Metolachlor is an important selective herbicide used for control of broadleaf and annual grassy weeds in a wide range of crops such as peanut, cotton, soybean, maize, and tomato. $S$-Metolachlor is a chiral compound comprised of $88 \% S$-enantiomer and $12 \% R$-enantiomer (Shaner et al., 2006). At the same application rate level, $S$-metolachlor is 1.4-1.6-fold more active than the metolachlor $(50 \% S$-enantiomer and 50\% $R$-enantiomer) (O'Connell et al., 1998; Grichar et al., 2001). Metolachlor has the potential to leach to groundwater because of its relatively high water solubility and low sorption to soil particles (Wu et al, 2011). Metolachlor and its metabolites had been frequently found in surface waters, such as streams, ponds, and wells, throughout the United States (Frank et al., 1990; Kalkhoff et al., 1998). Additionally, the data on bioaccumulation of metolachlor, particularly in edible fish species, have aroused enhancing concern about its safety to human health (Chesters, 1989). Therefore, numerous studies were carried out to investigate its adsorption, degradation, leaching, and mobility in soil (e.g., Wang et al., 1999; Sanyal and Kulshrestha, 1999; Spongberg et al., 2000; Rice et al., 2002; Si et al., 2009; Wu et al, 2011). However, there is very little information in the open literature on the environmental fate of $S$-metolachlor. Therefore, the present study was conducted to investigate the effects of several environmental factors, including soil properties, temperature, moisture, and microorganisms, and initial concentrations, on the rate of $S$-metolachlor degradation, and to propose application strategies for promoting $S$-metolachlor effectiveness on agricultural field weed control while minimizing harmful effects on the environment.

\section{Materials and Methods}

\subsection{Herbicide and soil}

The herbicide $S$-metolachlor $(97.7 \%$ purity) was purchased from Dima Technology Inc., USA. The five surface soils $(0-15 \mathrm{~cm})$ used in the study were collected from the agricultural fields where were never treated with $S$-metolachlor or other herbicides. All soils were air-dried, passed through 2-mm sieve, and stored at $20{ }^{\circ} \mathrm{C}$ before use. The soil sample was analyzed for characteristics following methodology outlined by $\mathrm{Lu}$ (2000). Selected physical and chemical properties of tested soils are shown in Table 1.

\subsection{Incubation experiments}

The degradation rate of $S$-metolachlor in soils under different conditions was determined based on the residual levels of the spiked herbicide after incubation. Briefly, soil samples $(20.0 \mathrm{~g}$ oven dry mass) were weighed into $100 \mathrm{~mL}$ tapered bottles. Soil in each tapered bottle was spiked with $S$-metolachlor at a concentration of $6 \mathrm{mg} \mathrm{kg}^{-1}$ (if not specified). Sterile distilled water was added to adjust to $60 \%$ water holding capacity (WHC). The bottles were then incubated for $0,7,14,30$ and $60 \mathrm{~d}$ at a controlled temperature $\left(25^{\circ} \mathrm{C}\right.$ if not specified). Soil moisture contents were measured and maintained to constant weight by adding an appropriate amount of distilled water, determined by weighing once each week. At each sampling time point, triplicate soil flasks were withdrawn from each treatment and immediately stored at $-20{ }^{\circ} \mathrm{C}$. 
Table 1. Selected characteristics of the five soils in this study.

\begin{tabular}{|c|c|c|c|c|c|c|}
\hline \multirow{2}{*}{ Soil } & \multirow{2}{*}{$\mathrm{OM}(\%)$} & \multirow{2}{*}{$\mathrm{CEC}\left(\mathrm{cmoL} \mathrm{kg}^{-1}\right)$} & \multirow{2}{*}{$\mathrm{pH}$} & \multicolumn{3}{|c|}{ Texture (\%) } \\
\hline & & & & Clay $0-2 \mu \mathrm{m}$ & Sand $2-50 \mu \mathrm{m}$ & Silt $50-2000 \mu \mathrm{m}$ \\
\hline $1 \#$ & $3.94 \mathrm{a}$ & $22.31 \mathrm{a}$ & $6.32 \mathrm{~b}$ & $26.23 \mathrm{a}$ & $53.26 \mathrm{a}$ & $20.51 \mathrm{~d}$ \\
\hline $2 \#$ & $2.72 \mathrm{~b}$ & $18.25 \mathrm{~b}$ & $5.15 \mathrm{~d}$ & $18.41 \mathrm{~cd}$ & $25.75 \mathrm{e}$ & $55.84 \mathrm{a}$ \\
\hline $3 \#$ & $2.08 \mathrm{c}$ & $12.16 \mathrm{~d}$ & $6.62 \mathrm{a}$ & $19.32 \mathrm{c}$ & $47.49 \mathrm{c}$ & $33.19 \mathrm{c}$ \\
\hline $4 \#$ & $2.01 \mathrm{c}$ & $18.45 \mathrm{~b}$ & $6.24 \mathrm{~b}$ & $21.24 \mathrm{~b}$ & $41.59 \mathrm{~d}$ & $37.17 \mathrm{~b}$ \\
\hline $5 \#$ & $1.22 \mathrm{~d}$ & $16.02 \mathrm{c}$ & $5.96 \mathrm{c}$ & $17.46 \mathrm{~d}$ & $50.35 \mathrm{~b}$ & $32.19 \mathrm{c}$ \\
\hline
\end{tabular}

CEC: cation exchange capacity. Different letters in columns indicate significant differences between treatments $(p<0.05)$.

The soil samples were mixed with $30 \mathrm{~mL}$ acetone-water $(25: 5, \mathrm{v} / \mathrm{v})$, shaken for $2 \mathrm{~h}$ on a reciprocating shaker and ultrasonically extracted for $20 \mathrm{~min}$, respectively. After filtration, acetone within the filtrate was allowed to evaporate. Solution of $2 \mathrm{~mL}$ was taken and passed through a $0.45 \mu \mathrm{m}$ membrane filter before highperformance liquid chromatograph (HPLC) analysis.

To examine the effect of soil properties the degradation rate of $S$-metolachlor, aliquots of the five tested soils $(1,2,3,4$, and $5 \#)$ were spiked with $S$-metolachlor, adjusted with sterile distilled water to $60 \% \mathrm{WHC}$, and incubated at $25{ }^{\circ} \mathrm{C}$ for up to $60 \mathrm{~d}$. Then procedures for sampling, extraction, and analysis were followed as described above.

To investigate the effect of soil moisture, after being spiked with $S$-metolachlor, air-dry $1 \#$ soil was adjusted with sterile distilled water to moisture levels of 20 , 40,60 , and $80 \% \mathrm{WHC}$, and incubated at $25{ }^{\circ} \mathrm{C}$ as described above.

The effect of soil microorganisms on $S$-metolachlor degradation was assessed by autoclaving 1 \#soil at $121{ }^{\circ} \mathrm{C}$ for $60 \mathrm{~min}$ for two times, and conducting the $S$-metolachlor incubation at $25{ }^{\circ} \mathrm{C}$ and $60 \% \mathrm{WHC}$ as described above. The degradation rate of herbicide was compared with that of the corresponding nonsterilized soil.

The effect of initial concentration on degradation of $S$-metolachlor in soil was determined by spiking $S$-metolachlor into $1 \#$ soil at 1, 3, 6, 9, 12, and 15 $\mathrm{mg} \mathrm{kg}^{-1}$ and determining the remaining levels of the herbicide after incubation at $25^{\circ} \mathrm{C}$ and $60 \%$ WHC.

\subsection{Analytical procedures}

The HPLC analyses were carried out using a Wasters $600 \mathrm{E}$ high-performance liquid chromatograph, equipped with Waters 2487 ultraviolet absorbance detector and a reversed phase $\mathrm{C}_{18}$ column $(150 \times 4.6 \mathrm{~mm}$ i.d., $5 \mu \mathrm{m})$. The eluting solvent was acetonitrile-water $(80-20, \mathrm{v} / \mathrm{v})$ at a flow rate of $1.2 \mathrm{~mL} \mathrm{~min}^{-1}$. The wavelength was set at $230 \mathrm{~nm}$ and the column temperature was kept at 30 ${ }^{\circ} \mathrm{C}$ for detection purpose. The injection volume was $5 \mu \mathrm{L}$. Each sample was analyzed in duplicate. The approximate retention time for $S$-metolachlor was 7.2 min. To assess the validity of $S$-metolachlor extraction method. Recovery was determined by spiking herbicide-free soil samples at four concentration levels of $0.05,0.5,5$, and $15 \mathrm{mg} \mathrm{kg}^{-1}$. In each fortification level, recoveries ranged from $83.17 \%-97.46 \%$ with relative standard deviation (RSD) less than $2.40 \%$. 
The minimum detection limit of $S$-metolachlor was 0.015 $\mathrm{mg} \mathrm{kg}^{-1}$. These data indicate that the extraction method is satisfactory for analysis of $S$-metolachlor residues.

\subsection{Statistical analysis}

The changes in residual concentrations of $S$-metolachlorin soil over time for each treatment were fitted to the first-order reaction kinetics model. The data were statistically analyzed by one-way analysis of variance (ANOVA). When statistical differences were observed, means were separated using least significant difference (LSD) test $(p<0.05)$.

\section{Results and Discussion}

\subsection{Soil types}

Soil factors influencing herbicide persistence include soil type, soil chemistry, and microbial activity. Soil type is a physical factor determined by the relative amounts of sand, silt, and clay in the soil as well as by the OM content. Soil type affects persistence through soil adsorption, leaching, and volatilization. Similar degradation behaviors of $S$-metolachlor were found for the five nonsterile soils (1-5\#) at a concentration of 6 $\mathrm{mg} \mathrm{kg}^{-1}$ (Figure 1).

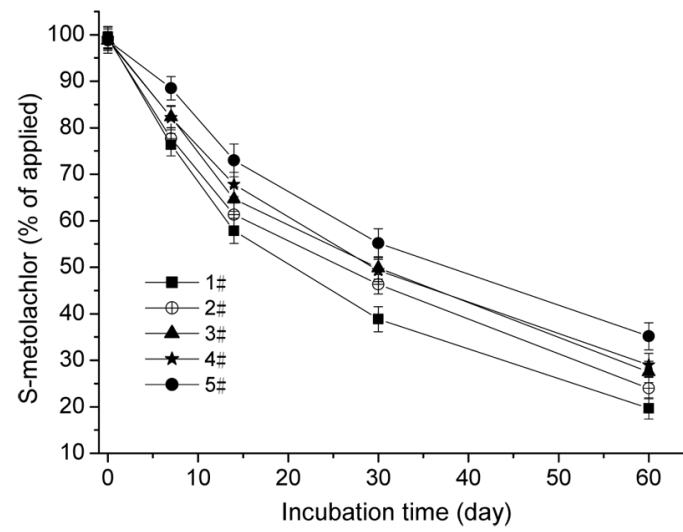

Figure 1. Degradation kinetics of $S$-metolachlor in soils with different soil types.
The decline of $S$-metolachlor in soils over time followed the first-order reaction kinetics model. The half-lives for $S$-metolachlor in the five soils, ranging from $26.3 \mathrm{~d}$ in $1 \#$ soil to $40.1 \mathrm{~d}$ in $5 \#$ soil (Table 2), were similar to those previously reported varying from 13 to $28 \mathrm{~d}$ (Shaner et al., 2006; Ma et al., 2006). In each case, $S$-metolachlor was more persistent in soils with lower OM content, compared to soils with higher OM content (Table 1). A significantly negative correlation was observed between the half-life and the soil OM content( $\mathrm{r}=-0.9746, p<0.01)$, suggesting that soil OM is predominant factor determining the persistence of $S$-metolachlor in soils. In contrast, soil texture, $\mathrm{pH}$, and CEC had little influence on the degradation rate of $S$-metolachlor in soil (Table 3). The increasing persistence of $S$-metolachlor in soils with decreasing OM content was in agreement with the previous results by Rice et al. (2002) and Wu et al. (2011) who attributed the degradation acceleration of metolachlor in soil with the relative high OM content to the relative large microbial population degrading metolachlor.

\subsection{Effect of temperature}

Soil temperature is one of the key climatic variables involved in herbicide degradation. Degradation rates of herbicide generally increase as temperature increase, because both chemical and microbial degradation. The effect of temperature on degradation of $S$-metolachlor in 1\#soil is depicted in Figure 2. In a range of 10 to $35^{\circ} \mathrm{C}$, the degradation rate of $S$-metolachlor $\left(6 \mathrm{mg} \mathrm{kg}^{-1}\right)$ at $60 \%$ WHC increased as temperature increased. At $10{ }^{\circ} \mathrm{C}, S$-metolachlor degraded fairly slowly, about $52.7 \%$ of the applied parent compound remained in soil after $60 \mathrm{~d}$ of incubation and its calculated half-life was $64.8 \mathrm{~d}$. In contrast, the half-life was reduced to $26.3 \mathrm{~d}$ at $25^{\circ} \mathrm{C}$. When the incubation temperature was elevated to 35 ${ }^{\circ} \mathrm{C}$, the half-life of $S$-metolachlor decreased to 23.7 d (Table 2). Obviously, the degradation rate of this herbicide in soil can be manipulated by controlling the temperature. 
Table 2. Degradation kinetic parameters of $S$-metolachlor in soil under different conditions.

\begin{tabular}{|c|c|c|c|c|c|}
\hline Soil & Temperature ( $\mathrm{C}$ ) & Moisture content $(\% \mathrm{WHC})$ & $r^{2}$ & $k\left(\mathrm{~d}^{-1}\right)$ & $T_{1 / 2}(\mathrm{~d})$ \\
\hline $1 \#$ & 25 & 60 & 0.9867 & 0.0264 & $26.3 \mathrm{~h}$ \\
\hline $2 \#$ & 25 & 60 & 0.9885 & 0.0228 & $30.4 \mathrm{~g}$ \\
\hline $3 \#$ & 25 & 60 & 0.9865 & 0.0208 & $33.3 \mathrm{f}$ \\
\hline $4 \#$ & 25 & 60 & 0.9919 & 0.0201 & $34.5 \mathrm{f}$ \\
\hline $5 \#$ & 25 & 60 & 0.9920 & 0.0173 & $40.1 \mathrm{~d}$ \\
\hline $1 \#$ & 10 & 60 & 0.9984 & 0.0107 & $64.8 \mathrm{~b}$ \\
\hline $1 \#$ & 15 & 60 & 0.9927 & 0.0178 & 38.9 ef \\
\hline $1 \#$ & 35 & 60 & 0.9835 & 0.0293 & $23.7 \mathrm{i}$ \\
\hline $1 \#$ & 25 & 20 & 0.9986 & 0.0176 & $39.4 \mathrm{e}$ \\
\hline $1 \#$ & 25 & 40 & 0.9930 & 0.0209 & $33.2 \mathrm{f}$ \\
\hline $1 \#$ & 25 & 80 & 0.9879 & 0.0296 & $23.4 \mathrm{i}$ \\
\hline 1 \#, sterilized & 25 & 60 & 0.9967 & 0.0079 & $87.7 \mathrm{a}$ \\
\hline $1 \#, 1 \mathrm{mg} \mathrm{kg}^{-1}$ & 25 & 60 & 0.9838 & 0.0366 & $18.9 \mathrm{j}$ \\
\hline 1 \#, $3 \mathrm{mg} \mathrm{kg}^{-1}$ & 25 & 60 & 0.9856 & 0.0301 & $23.0 \mathrm{i}$ \\
\hline 1 \#, $9 \mathrm{mg} \mathrm{kg}^{-1}$ & 25 & 60 & 0.9900 & 0.0230 & $30.1 \mathrm{~g}$ \\
\hline $1 \#, 12 \mathrm{mg} \mathrm{kg}^{-1}$ & 25 & 60 & 0.9802 & 0.0191 & $36.3 \mathrm{f}$ \\
\hline $1 \#, 15 \mathrm{mg} \mathrm{kg}^{-1}$ & 25 & 60 & 0.9927 & 0.0151 & $45.9 \mathrm{c}$ \\
\hline
\end{tabular}

$k$ : degradation rate constant; $r^{2}$ : coefficient of determination. Different letters in columns indicate significant differences between treatments $(p<0.05)$.

Similar relationships between temperature and degradation have been demonstrated in the cases concerning herbicides such as metolachlor (Rice et al., 2002) and isoxaflutole (Taylor-Lovell, et al., 2002). These data show that while soil microbial abundance and activity is a function of temperature. The types of microorganisms (fungi, bacteria, protozoans, etc.) and their relative numbers determine how quickly decomposition occurs. Microorganisms require certain environmental conditions for optimal growth and utilization of any herbicide. Factors that affect microbial abundance and activity are moisture, temperature, $\mathrm{pH}$, oxygen, and mineral nutrient supply. Usually, a warm, well-aerated, fertile soil is most favorable for microbial growth and, hence, for herbicide dissipation (Rice et al., 2002; Taylor-Lovell, et al., 2002). This indicates that on warm days the soil surface, especially when covered by transparent plastic films in the vegetable, maize, or soybean field, usually is much warmer than underlying soils. Enhancing degradation of $S$-metolachlor will mitigate its surface runoff with the soil and leaching through the soil, and hence decrease surface and ground water pollution of the herbicide. 
Table 3. Relation between degradation half-lives of $S$-metolachlor and soil property parameters.

\begin{tabular}{cccc}
\hline Parameter & Regression equation & $r$ & $p$ \\
\hline OM & $\mathrm{y}=44.6621-4.9048 \mathrm{x}$ & -0.9746 & 0.0048 \\
CEC & $\mathrm{y}=47.0775-0.8119 \mathrm{x}$ & -0.5909 & 0.2941 \\
pH & $\mathrm{y}=31.2202-0.2806 \mathrm{x}$ & 0.0307 & 0.9609 \\
Clay & $\mathrm{y}=55.7416-1.1115 \mathrm{x}$ & -0.7568 & 0.1386 \\
Sand & $\mathrm{y}=30.3719-0.0583 \mathrm{x}$ & 0.1246 & 0.8417 \\
Silt & $\mathrm{y}=31.5059-0.0395 \mathrm{x}$ & 0.0992 & 0.8739 \\
\hline
\end{tabular}

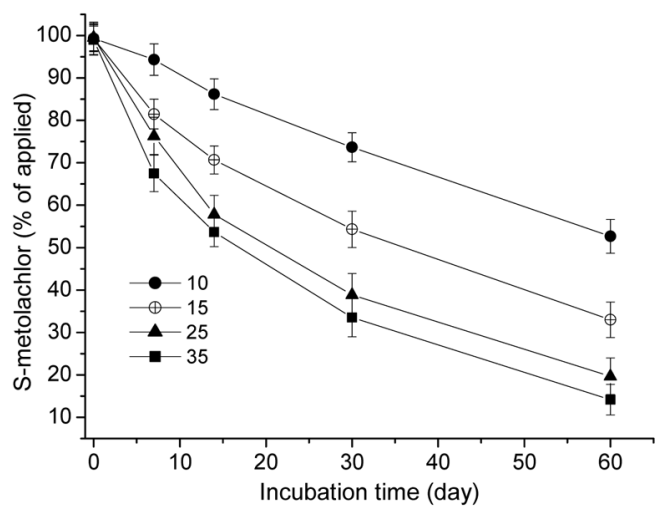

Figure 2. Degradation kinetics of $S$-metolachlor in 1 \#soil as affected by temperature.

\subsection{Effect of moisture}

Soil moisture is a major factor determining diffusion and persistence of herbicides. Increasing soil moisture will reduce the pores available for herbicide diffusion. Meanwhile, higher moisture contents favor more herbicide partitioning in the aqueous phase, which is readily subject to biotic and abiotic degradation. The results from the incubations of $S$-metolachlor in 1 \#soil with varying soil moisture levels also gave good approximations to the first-order kinetics (Figure 3) and the data are summarised in Table 2.

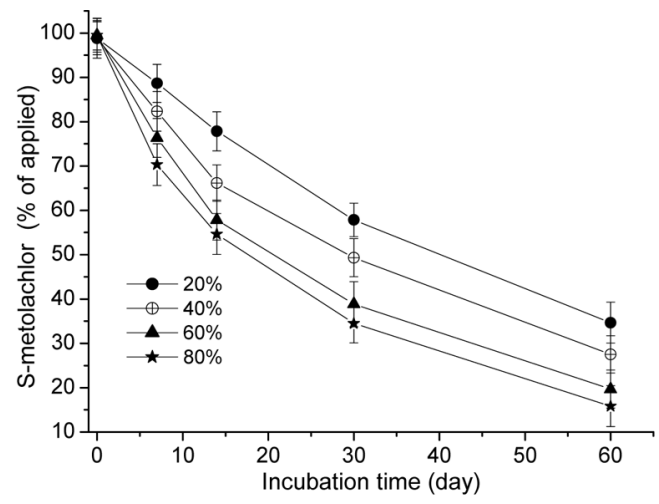

Figure 3. Degradation kinetics of $S$-metolachlor in 1 \#soil at different moisture levels.

The half-life varied from $39.4 \mathrm{~d}$ at $20 \%$ WHC to $23.4 \mathrm{~d}$ at $80 \%$ WHC. Low levels of moisture, such as $20 \% \mathrm{WHC}$, may limit the microbial activity and the amounts of $S$-metolachlor in solution. Moisture level of $60 \%$ WHC may give enough water for microbial processes and solubilization of the herbicide. At $80 \%$ WHC, soil moisture conditions near water saturation are expected with associated oxygen deficiency in the system. Under these conditions aerobic microbial processes will be limited and anaerobic processes may prevail. Thus, the increases in the moisture level resulted in fast biodegradation of $S$-metolachlor. 
Soil parameters are subject to some degree of spatial and temporal variability, but soil moisture probably exhibits the most dramatic fluctuations over space and time. Fluctuations in soil moisture may affect rates of biodegradation directly by altering the physiological status of microorganisms. The effect of soil moisture content on rates of degradation of pesticides in particular is well documented (e.g.,Shelton and Parkin, 1991; Walker et al., 1992; Rice et al., 2002; Castillo and Torstensson, 2007). Decreasing levels of soil moisture have consistently been observed to retard or inhibit rates of microbial metabolism, although the pattern or degree of inhibition is dependent upon the substrate, microbial process, or nature of the microflora. These data indicate that soil moisture may influence rates of biodegradation either directly by inhibition of microbial activity or indirectly by affecting substrate bioavailability (Shelton and Parkin, 1991).

\subsection{Effect of soil microorganisms}

The changes in remaining levels of $S$-metolachlor in $1 \#$ sterilized and unsterilized soil at $25{ }^{\circ} \mathrm{C}$ and $60 \%$ WHC over time were illustrated in Figure 4. Degradation of $S$-metolachlor in sterile soil was also fitted to the first-order kinetics (Table 2). As expected, additional sterilization treatment led to a significant decrease in the degradation rate of $S$-metolachlor in the soil investigated. The residual quantities of $S$-metolachlor in sterilized soil were significantly larger than those in nonsterilized soil over the entire period of observations except at the beginning (Paired t test, $p<0.05$ ). The sterilization increased the half-life from 26.3 to $87.7 \mathrm{~d}$, or by $70.01 \%$. The first-order rate constant in nonsterilized soil was 3.3 times larger than that in sterilized soil, suggesting that the degradation by soil microorganisms are probably the most important pathway responsible for breakdown of $S$-metolachlor. The results obtained here comparing the sterilized and unsterilized soils confirm the findings of Rice et al. (2002) and Wu et al. (2011) who have demonstrated that the degradation rate of metolachlor was significantly decreased in autoclaved soils.

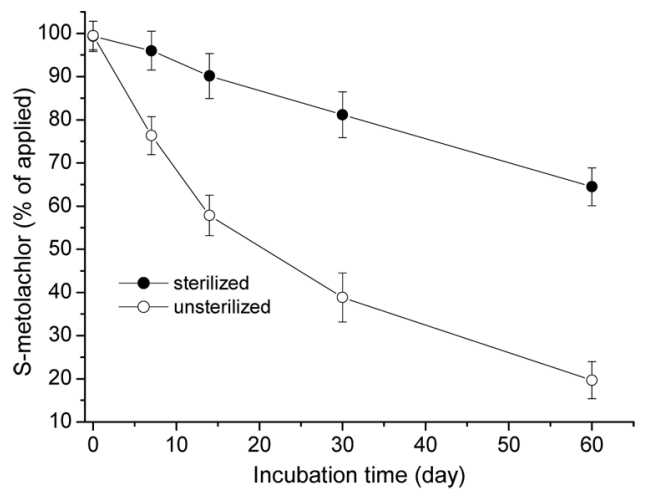

Figure 4. Degradation kinetics of $S$-metolachlor in 1 \#sterilized and unsterilized soil.

Surface soils that are rich in organic matter favor the growth of heterotrophic microorganisms (Rice et al., 2002). Konopka and Turco (1991) observed that microbial biomass declined by several orders of magnitude with soil depth. Biodegradation has been shown to be the primary mechanism of metolachlor degradation in soil (Ma et al., 2006; O'Connell et al., 1998; Rice et al., 2002; Shelton and Parkin, 1991; Taylor-Lovell, et al., 2002; Wu et al., 2011). In fact, repeated soil applications of metolachlor have been found to result in adapted microbial populations having an enhanced ability to degrade metolachlor (Sanyal and Kulshrestha, 1999). Therefore, factors that influence microbial abundance and activity in surface soil, may affect the persistence of $S$-metolachlor.

\subsection{Effect of initial concentrations}

The degradation kinetics of $S$-metolachlor with different initial concentrations or application rates in 1 \#soil at $25{ }^{\circ} \mathrm{C}$ and $60 \% \mathrm{WHC}$ is shown in Figure 5. Degradation of $S$-metolachlor at each concentration could be described by first-order kinetics (Table 2). A general trend existed that the degradation rate constant decreased with increasing the initial concentration. The half-lives of $S$-metolachlor for the 6 application levels varied 2.4-fold from 18.9 to 45.9 
$\mathrm{d}$, which suggesting that degradation of this herbicide in soil was dependent on the initial concentration. It is commonly accepted that degradation of herbicides in soil reflects a combination of microbiological processes, chemical reactions with soil constituents, and hydrolysis (Baer and Calvet, 1999). Under the same condition, therefore, $S$-metolachlor degradation may significantly affected by the initial concentration because of shifts in activity of $S$-metolachlor-degrading microorganisms. The higher initial concentrations are, the severer the microbial activity will be suppressed. In a detailed study, Hance and McKone (1971) reported that degradation of herbicides (atrazine, linuron and picloram) when incubated with two soils at four levels of application for periods of 3 or 4 months. In each case the herbicide degradation rate was founded to decrease as the initial concentration increased. In a comparable experiment, Ma et al. (2001) demonstrated that the 1, 3 -D degradation rate in soil obeyed the degradation rate decrease with increasing the application level. In other studies, similar results have been found between initial concentrations and degradation rates for sulfadimethoxine (Wang et al., 2006) and methyl iodide (Guo and Gao, 2009). Considering that the application rate affects atmospheric volatilization and soil degradation of chemicals, $S$-metolachlor and other field-applied herbicides should be applied at the lowest rate that achieves satisfactory weed control.

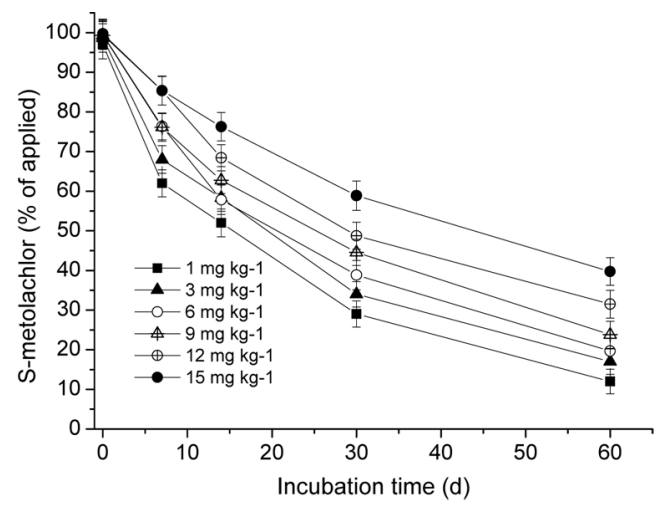

Figure 5. Degradation kinetics of $S$-metolachlor in 1 \#soil as affected by initial concentration.

\section{Conclusions}

Herbicide efficacy and environmental fate are often controlled by degradation However, degradation of herbicide in soil is a complex process that is influenced by various factors, including soil properties, climatic conditions, and herbicide characteristics. Laboratory incubation experiments showed that degradation of $S$-metolachlor in soil could be described by the firstorder kinetics, while the degradation rate was mainly controlled by soil OM, temperature, moisture and initial concentrations. Soil OM greatly facilitated degradation of $S$-metolachlor. Decreasing temperature and moisture resulted in prolonging the half-life of $S$-metolachlor in soil. Microbial degradation played a role in the persistence of $S$-metolachlor in soil. Additionally, soil degradation of $S$-metolachlor was dependent on initial concentrations. To reduce translocation to surface and ground water, this herbicide should be conducted at a minimum effective application rate considering the differences between soil properties, especially soil $\mathrm{OM}$, temperature and moisture.

\section{Acknowledgments}

This work was supported by the National Natural Science Foundation of China (No.21267007, 31000204), the Agricultural Research Projects of Science and Technology Department of Guizhou Province (No. (2009)3022, [2012]3010), the Science and Technique Foundation of Guizhou Province (No. [2010]2074), and the Senior Talent Introduction Research Program of Guizhou University (No. (2011)06).

\section{References}

Baer, U., Calvet, R. 1999. Fate of soil applied herbicides: experimental data and prediction of dissipation kinetics. J. Environ. Qual. 28(6), 1765 1777. 
Baker, J.L., Mickelson, S.K. 1994. Application technology and best management practices for minimizing herbicide runoff. Weed Technol. 8(4), 862-869.

Castillo, M.P., Torstensson, L. 2007. Effect of biobed composition, moisture, and temperature on the degradation of pesticides. J. Agric. Food Chem. 55(14), 5725-5733.

Chesters, G., Simsiman, G.V., Levy, J., Alhajjar, B. J., Fathulla, R. N., Harkin, J. M. 1989. Environmental fate of alachlor and metolachlor. Rev. Environ. Contam. Toxicol. 110, 1-74.

Shaner, D.L., Brunk, G., Belles, D., Westra, P., Nissen, S. 2006. Soil dissipation and biological activity of metolachlor and S-metolachlor in five soils. Pest Manag. Sci. 62(7), 617-623.

Frank, R., Braun, H.E., Clegg, B.S., Ripley, B.D., Johnson, R. 1990. Survey of farm wells for pesticides, Ontario, Canada. Bull. Environ. Contam. Toxicol. 44(3), 410-419.

Gaultier, J., Farenhorst, A., Cathcart, J., Goddard, T. 2008. Degradation of [carboxyl- ${ }^{14} \mathrm{C}$ ] 2, 4-D and [ring-U- ${ }^{14} \mathrm{C}$ ] 2, 4-D in 114 agricultural soils as affected by soil organic carbon content. Soil Biol. Biochem. 40(1), 217-227.

Grichar, W.J., Lemon, R.G., Brewer, D., Minton, B.W. 2001. S-Metolachlor compared with metolachlor on yellownutsedge (Cyperus esculentus) and peanut (Arachis hypogaea). Weed Technol. 15(1), 107-111.

Guo, M.X., Gao, S.D. 2009. Degradation of methyl iodide in soil: effects of environmental factors. J. Environ. Qual. 38(2), 513-519.

Hance, R.J., McKone, C.E. 1971. Effect of concentration on the decomposition rates in soil of atrazine, linuron and picloram. Pesti. Sci. 2(1), 31-34.
Kalkhoff, S.J., Kolpin, D.W., Thurman, E.M., Ferrer, I., Barcelo, D. 1998. Degradation of chloroacetanilide herbicides: the prevalence of sulfonic and oxanilic acid metabolites in Iowa groundwaters and surface waters. Environ. Sci. Technol. 32(11), 1738-1740.

Konopka, A., Turco, R. 1991. Biodegradation of organic compounds in vadose zone and aquifer sediments. Appl. Environ. Microbiol. 57(8), 2260-2268.

Lu, R. K. 2000. Methods of soil and agrochemistry analysis, Chinese Agricultural Science and Technology Press, Beijing.

Ma, Q.L., Gan, J., Papiernik, S.K., Becker, J.O., Yates, S.R. 2001. Degradation of soil fumigants as affected by initial concentration and temperature. J. Environ. Qual. 30(4), 1278-1286.

Ma, Y., Liu, W.P., Wen, Y.Z. 2006. Enantioselective degradation of Rac-metolachlor and $S$-metolachlor in soil. Pedosphere. 16(4), 489-494.

O'Connell, P.J., Harms, C.T., Allen, J.R.F. 1998. Metolachlor, $S$-metolachlor and their role within sustainable weed management.Crop Protect. 17(3), 207-212.

Rice, P.J., Anderson, T.A., Coats, J.R. 2002. Degradation and persistence of metolachlor in soil: effects of concentration, soil moisture, soil depth, and sterilization. Environ. Toxicol. Chem. 21(12), 2640-2648.

Sanyal, D., Kulshrestha, G. 1999. Effects of repeated metolachlor applications on its persistence in field soil and degradation kinetics in mixed microbial cultures. Biol. Fertil. Soils. 30,124-131.

Shelton, D.R., Parkin, T.B. 1991.Effect of moisture on sorption and biodegradation of carbofuran in soil. J. Agric. Food Chem. 39(11), 2063-2060. 
Si, Y., Takagi, K., Iwasaki, A., Zhou, D. 2009. Adsorption, desorption and dissipation of metolachlor in surface and subsurface soils. Pest Manag. Sci. 65(9), 956-562.

Spongberg, A.L., Lou, G.L. 2000. Adsorption of atrazine and metolachlor in three soils from Blue Creek wetlands, Waterville, Ohio. Sci. Soils. 5 (1), 1-9.

Taylor-Lovell, S., Sims, G.K., Wax, L.M. 2002. Effects of moisture, temperature, and biological activity on the degradation of isoxaflutole in soil. J. Agric. Food Chem. 50(20), 5626-5633

Thurman, E.M., Goolsby, D.A., Meyer, M.T., Mills, M.S., Pones, M.L., Kolpin, D.W. 1992. A reconnaissance study of herbicides and their metabolites is surface water of the Midwestern United States using immunoassay and gas chromatography/mass spectrometry. Environ. Sci. Technol. 26(12), 2440-244
Walker, A., Moon, Y.H., Welch, S. J. 1992. Influence of temperature, soil moisture and soil characteristics on the persistence of alachlor. Pestic. Sci. 35(2), 109-116.

Wang, Q., Guo, M., Yates, S.R. 2006. Degradation kinetics of manure-derived sulfadimethoxine in amended soil. J. Agric. Food Chem. 54(1), $157-$ 163.

Wang, Q.Q., Yang, W.C., Liu, W.P. 1999. Adsorption of acetanilide herbicides on soils and its correlation with soil properties. Pestic. Sci. 55(11), 1103-1108.

Wu, X.M., Li, M., Long, Y.H., Liu, R.X., Yu, Y. L., Fang, H., Li, S.N. 2011. Effects of adsorption on degradation and bioavailability of metolachlor in soil. J. Soil Sci. Plant Nutr.11 (3), 83-97.

Zheng, S.Q., Cooper, J.F. 1996. Adsorption, desorption, and degradation of three pesticides in different soils. Arch. Environ. Contam. Toxicol. 30(1), 15-20. 